\title{
The Expressive Energy of Arabic Through Metaphors: Linguistic and Stylistic
}

\author{
Dr. Abeer Obaid Al-Shbail \\ Jordan - Balqa Applied University
}

\author{
DOI: $10.7176 / J L L L / 62-06$ \\ Publication date: November $30^{\text {th }} 2019$
}

\section{The importance and justification of the research}

The first objective of this study is to analyze the nature of linguistic thinking among the Arabs, which helped them to form a nation of intellectual and civilization formation through a culture of its Arabic campaign to the world. As long as the Persians from the circulation of knowledge, and removed the languages of the peoples of the State of the Caliphate, and there is no evidence that the linguists and philosophers Muslim learned, and mastered, and created them.

The second goal was to stand at the major rules on which Arab scholars based, in the Middle Ages "from the second to the sixth century AH" These rules and foundations are suitable for non-language in terms of curriculum, especially in their study of the nature of language, and distinguish language from speech, through criteria They developed it, then developed it until it became valid for generalization, assay and conclusion.

In the third end, we sought to follow the efforts of linguists, grammarians, and rhetorists to extract a comprehensive basis for the study of "semantics", which compelled them to use science from outside the language "logic" and "natural" to enhance their ability to extrapolate and analyze from the "reality" of the text, and even within it I found out the possibility of generalization ...

As for the standing on "truth and metaphor" was the main purpose of the research, and therefore we stopped at the explanations of linguists and rhetoric and their analysis of verses from the wise Quran, and then reviewed their ability to measure between the "text" of the Quran and the words of the Arab poetry and prose, and we entrusted the research towards the methodology of the big and IbnQutaiba and Jurjani imams of Curriculum, language and statement who studied language at the "singular" level and at the "syntax" level.

We did not fail to distinguish between the metaphors: stylistic and linguistic, and come to the characteristics of each of them, that - if separated - constitute the unity of Arab rhetorical thinking.

\begin{abstract}
Approach
We proceeded from the conviction that each "text" or subject has a method that can penetrate it. The researcher may have to use another method, in order to complete the bases of objective research, we have resorted to the "integrative" approach because of the nature of research that abuts a non-subject of language,grammar, statement, Albadie, singular and synthesis, truth and metaphor, significance and logic, and philosophy, we have used the right of integration analysis and comparison, especially after we saw him adopted by the fur and Abu Obeidah on his left, and did not overlook the historical method as part of the subject of research, it is issued from the scientific community, and about the other social creative from linguistic, grammatical, rhetorical and philosophical, it foretells the researcher on the temporal phases of the applied research, and the climate that surrounded the writer or author, and pushed him to research, has helped us the historical approach to read "experimentation" of Arab scientists sequential reading, If the first led to the end.
\end{abstract}

\section{The Search}

The word - on the truth - is the word used in convention of speech, we said: "used" as a precaution of what was not used, the word before use is not called a fact, and we said: "In what I described," a precaution of two things: one used in what is not I put him wrong, as if you want to tell your friend: Take this book "the book with your hands" you were mistaken, you said: "Take this horse." And the second one of the two sections of the metaphor, which was used in what was not the subject of it, not in the convention of speech, or in other, such as the word "lion" in the brave man, and we said: "convention of speech" as a precaution against the other section of the metaphor, which was used in Put him in a term used as the word "prayer" used by the addressee to know the law in the metaphor metaphorically, and the situation set the word to denote the meaning himself, we say "himself" as a precaution of the designation of the word to denote the meaning of his definition, I mean metaphor, that appointment is not called a situation $\left({ }^{1}\right)$.

And metaphorically - lexically - is the expression of speech, and from speech beyond what has set meaning,

${ }^{1}$ Khatib al-Qazwini - clarification in rhetoric science - achieve d. Abdel Hamid Hendawy - Foundation Mukhtar for Publishing and Distribution - Cairo - 1-1999- p. 243 
but the "Al Mujeez" is the values of others, and the triple "Jaws" in which many, the most important - here - may say nuts and metaphor: accepted and implemented and went on health, and Poetry authorized the poet in the poem: contrary to the verses movement character that follows the character of Roy, and in the hadeeth: "I authorize myself today witness only Mona" $\left({ }^{1}\right)$.

The word "metaphor"(Al Majaz) was not the usual word in the vocabulary of the Arab sciences, and it is likely that the Arab sciences have received this word, as a term through "transfer" like other terms that left the original position to new positions, imposed by the systems of contexts and scientific and cultural needs emerging in Arab - Muslim Societies.

The word has two forms: the first with Hamz (Hamza mode), and the second without hamzs, it says: I Joz'tAlBaida. And it is permissible for the road and walnut and permissible, and metaphor, and says: I approved the position. The two forms show the same meaning, and it is clear that the idiomatic meaning of "metaphor" is only a combination of the two meanings of the word: transition, and permissible thing metaphor of the other.

\section{Language and Open Borders:}

Language as a human phenomenon is subject to the conditions of change and evolution, and the transition from one case to another. The word is a continent in "private" and its significance moves to "general". The word "language" does not depart from the context of development and change. It responds to different needs, including idiomatic needs. It took time not a little, and through different historical stages.

Obviously, tracing semantic development offers researchers many benefits, the most important of which is scheduling linguistic research, The fledgling meanings of the contexts are cleavage, including showing the links between words that have become "terms" and often used in one sense, such as "language" and "speech" The semantic research is the difference between the language systems, and the performance of native speakers, and this is a factor enriching the language and functions with the owners, and the language researcher, "Dr. Ibrahim Anis" that "the word language" was not used in the old sense in the sense that we know today ... The ancient Arabs in the ages of ignorance and when Islam was issued times did not express what we call "The language" except with the word "tongue", that word common pronunciation and meaning in most Semitic languages Arabic sisters " $\left({ }^{2}\right)$

As for the "Idiocy", the bonds between it and "speech" appeared in Al-Khleel in the "Al Ayn" and IbnManthour in the "Al Lesan" and Al-Khleel died in 175 AH and IbnManthour late in "717 AH-1311 AD," both of which proved the connection between "Gh" and" and "speech" "From the Al-Khleel saying:" Language, languages : are difference of speech in one sense " $\left({ }^{3}\right)$. In the words of the Almighty - Al-Furqan - 72: (And if they passed through the language they passed dignity), The meaning of rhetoric here is "falsehood, and in the hadith: "Whoever says on Friday and Imam is preaching: Sahih, he has canceled" means talking, and the hadeeth is narrated in SaheehAl-Bukhaari, 8/48. So the subject "L-Gh-W" is related to the meaning of speech, and in another prophetic hadeeth: "Whoever touches the Hasa has lost language", meaning he speaks, it was said: "Righteousness" is correct $\left({ }^{4}\right)$.The term "idiocy" is closely related to "speech" and is a function of one of its attributes, Al-Khleel interpreted the "language" as a difference of speech in one sense, has been quoted by AlAzhari in the "Politeness" said: "oblivious to the right, and the road, as he tended him", and Ibn al-A'rabi said: "The language was taken who is this". Al-Lesan"part15-255.

As for the dialect, it is a way of pronunciation, or formulation they take within the language spoken by the people, Al-Khaleel has said: "It is said eloquent dialect, which is the language on which it was raised and grew up" $\left({ }^{5}\right)$. Here, Al-Khaleel has interpreted the dialect of language, but in the stages following the founding phase of language science, especially after the second century $\mathrm{AH}$, as the distance between the language and dialect begins to grow and widen, until the complete separation determined by the new and emerging context, contemporary researchers have shown that The ancients went through successive stages, the most important of which are: collection, recording, tabulation and lesson. Also, the researcher needs in the stages of his research to terminology, and begins to rid the meanings of each other, and use some vocabulary in the first connotations conceived by the speakers of the language, but then needs to use these vocabulary in broader connotations. The mind forgets the steps of moral development that have gone through, if we recognize that it was known one day, and words always have a meaningful presence limited to the moment they are used, and a singular use of the temporary use in which $"\left({ }^{6}\right)$.

Ibrahim Anis believes that the dialect is the set of linguistic traits that belong to a particular environment,

\footnotetext{
${ }^{1}$ Intermediate Dictionary - part 1 - p. 152 - c3 - Cairo 1960.

${ }^{2}$ In Arabic dialects, pp. 17-2003, Dar Al Fikr Al Arabi, Egypt, Cairo, Al Resala Press

${ }^{3}$ Al-Ain - c4 - p449 - Appendix c8 - investigation Abdul Hamid Hindawi - Scientific Books House - 1973.

${ }^{4}$ Ibn al-Atheer - strange modern and impact - c14 - p 285 - Scientific Library - Beirut - 1979 - achieve angular.

${ }^{5}$ Lexicon of the eye - 13 - 391 - a previous source.

${ }^{6}$ Subhi Al-Saleh - Studies in Philology - House of science for millions - I 10 - 1983 - p 305.
} 
and are shared by all members of the environment $\left({ }^{1}\right)$. This view does not differ from a contemporary scholar from the result of Khalil bin Ahmed in the second century, was the view that the characteristics of the dialect is the result of a difference in speech between the tribe and another, Hzayel acquired its characteristics from its Hijazi origins, and then differentiate them commensurate with the temporal and spatial development, and dialects - even When it is spaced - it is not far from the original, which is the "mother tongue", ie "Arabic". The contrast between the dialects is due to the meanings that the dialects want to express in their methods $\left({ }^{2}\right.$.

It is worth mentioning that Sibawayh used the word "language" in the meaning of the "dialect" in the misplaced part of his book, such as saying: (This is no a human) being in the language of the people of Hijaz, and BaniTamim raise it, but who knows how it shown in the Quran $\left(^{3}\right)$. The distance between the compositions, Hijazi and Tamimi refers to the difference of speech while maintaining one meaning, as Sibawayh and SheikhAl-Khaleel, the Hijazis do "Ma", and they liken it to "not" if its meaning as its meaning, while the Tamimis conduct it as "Ama", and Sibwayh mentioned a number of dialectal differences on the level of expression as in the previous example, and on the level of grammer as in "Bia,Qeel" it was said "Yaqoul," and some Arabs say: DaifwaBia, it will show that it is "an act" and some say: Boa, Khawf, Qawl, hop, the B followed by what before, as he said: "Maw'qef" some differences on the voice level, and so what came In the section, "Arabs differ in moving the other because it is not right to silence and the first non-people of the Hijaz. $\left({ }^{4}\right)$ " and IbnJeni 392 AH entrenches by saying " It's limit is the voices of all people express their purposes, this alone, but the difference when it will be mentioned in the door to say it: Placement or inspiration, but the grammer and knowledge of its letters is an Fu'la of laghout, means spoke, and the origin is lagh'wa as a ball, as I have demonstrated in my book "The mystery of industry "was said to be canceled, if canceled, and its source" Al Lagha " $\left({ }^{5}\right)$.

In the second half of the fifth century AH 450-504, the Shafi'i jurist Emad Al-Din, known as the "Kaya Harassi", in Muada opinion that "language is human voices ... This speech is a letter and a voice, from the lung to the mouth, and they found it twenty-nine characters, not more than on that, and then divided it on the throat, chest, lip and gums, and then saw that the efficiency does not fall in these letters, It does not make him intended in the income, mention them, Speech bilaterally, triangularly, quadruple and pentagonal, this is the origin of the structure $"\left({ }^{6}\right)$.

As for IbnHazmAl-Andalusi 384-456AH994-1064 AD, also limited the language by his position as a qurtubijurist "The language is cherished by all folk about the nomenclature and the meanings to be understood. The word is all that moved by the tongue." ${ }^{7}$ The word does not stand at the letter or the word used or when the other neglected, but it is spoken by the tongue, but the grammatical have evidence of what is going on from the provisions of the grammar, such as compassion and substitution and conscience due excitement ...

TheAl-JurjaniAbdAl-Qahera 400-741 AH-1009-1078 AD, the known speaker, grammar and rhetoric, says in the pronunciation: "If we assume that these words, which are languages, would not be removed, none of them would be worthy of submission." $\left.{ }^{8}\right)$

Al-Hajeb (570-646AH-1174-1249 AD), the jurist Al-Maliki and the grammarian say: "Every language has a meaningful meaning." If it comes to denying it, it benefits the whole of its members, and it has no indication except for the inclusiveness of each individual $\left({ }^{9}\right)$. Linguists, rhetorists, and jurists have each turned to the language that suits them. The grammarians went on to study the vocabulary within the complex structure, while the rhetorists and theologians went on to study the words individually and composite.

\section{Language .. Origin and Truth:}

The word "origin" is repeated in the body of Arabic blogs, especially linguistic ones, and this word was not accurate in the perceptions of the ancients, but it was a general concept without definition or definition, as an abstract idea, or a mental image diagnosed in the applied fields, as any law in nature or, in culture, it starts from the repeated observation, with regard to individual images changing their indications according to their behavior, or assigning them to pronouns, Deuteronomy or plural, and then they tried to search for the "root" that does not change, and this led them to the stereotype of the sentence, which Proven despite additions, deletions or damaging and named the origin of the letter and the origin of the Wigs and wholesale origin as the collector is

\footnotetext{
${ }^{1}$ In Arabic dialects - p. 16 - a previous source.

${ }^{2}$ For more information see Al-Mizhar in Al-Suyuti language sciences, part 2, p. 297- Achieving Mohamed Gad El-Mawla, Mohamed AboulFadl Ibrahim, Ali El-Bejaoui, Modern Library, Cairo.

${ }^{3}$ Book - part 1 - pp. 57--59.

${ }^{4}$ Al-Mizhar, previous source, c. 2 , p.

${ }^{5}$ Characteristics - part 1 - p33 - door in saying on the language and what is - Dar al-Huda - Beirut - 1970.

${ }^{6}$ See Al-Mizhar, Part 1-36-37, for Suyuti in more about the views of Alhrassi.

${ }^{7}$ Provisions - part 1/52 - Bowl - Mawardi - investigation Ahmed al-Baghdadi - Dar IbnQutaiba - Kuwait - 1989.

${ }^{8}$ Vidence of miracles - p50 - Investigation Mahmoud Shaker - Khanji Library - Cairo.

${ }^{9}$ Guiding minds to achieve the right from the science of origins - Mohammed Al-Shawkani - Achievement Ahmed EzzoEnaya - Damascus - $\mathrm{p}$. 118 - in 2000.
} 
"out of the situation" $\left({ }^{1}\right)$. The origin of the situation predicts the structure of the singular, and the structure of the structure together, which at the same time reveals the origin of the "meaning" and the relationship between the singular and its name, or the significance of the composition of the first meaning, which stood by the grammarians and meanings.

Al-Farahidi 176 AHin "Al-Ain" had alerted before others to the rules through which the semantics of the vocabulary are traced, and Sibawayh pointed out that "as if he had glimpse his insight that the various phenomena of languages are organized by hidden threads, and these major lines are bifurcated by the threads that are below them, which made them Duly, and make the rest branches " $\left({ }^{2}\right)$.

Since the abstract words do not perform the task of circulation, exchange and understanding, it was necessary to be the synthesis of the whole of the speaker or writer, the words are used according to the semantics originally agreed upon, and at other levels the user exits the words from the semantic field to new semantics. AlJahez referred to this phenomenon by saying: "The rule of meanings is a dispute ruling on vocalizations, because meanings are simplified to infinity, and extended to infinity, and the names of meanings are numbered, and the result is limited ${ }^{3}{ }^{3}$, and through observation found to scientists and grammarians and rhetoric that the speaker dealing with the singular significance must be issued by the origin of this connotation beyond New meanings, hence the rhetoric and grammarians talked about the origin of language and the issue of the relationship between the name and the name.

Sibawayh in $195 \mathrm{AH}$ has collected types of speech, and make them in sections, each section has its structural characteristics that correspond to the rule, or do not correspond, he said: "This is the door of integrity of speech and referral, from which a good straight and assigned, and a straight lie, and a straight ugly, and what is assigned and lied." $\left({ }^{4}\right)$, The Good Straight is what was the word and its meaning is correct, and came on the rules of thinking and composition as saying: I came yesterday and I come to you tomorrow, but the assignment invalidates the first words last says: "I came tomorrow and I come yesterday," The rectum lying like you said I drank the river, and may be consistent talk With the synthetic base, but not consistent with the meaning, but the lying shop "as you say: I will carry the mountain yesterday", What is understood from the words of Sibawayh consistency of the validity of the composition with the consistency of the validity of meaning.

\section{Syntax and Fact of Language:}

In his integrated work "towards, purely, eloquently", Sibawayh consistently sought the "assets" adopted by the speaker and spoke about them in his speech addressed to others. The other concerned either directly or indirectly, he had in his mind the abstract assets that he assumed. They exist in the mind of the speaker, and the abstract origins did not reach them alone, but benefited from his experience with Sheikh Al-Farahidi in extrapolation.

Sibawayh adopted "inference" in understanding the extraction of the rule, as he collected the examples corresponding to the rule, to be a witness to its validity, and the base has an abstract suggesting the ideal wording that speaks, and the door "predicate" is a witness to the method of Sibawayh, it comes to the abstract rule, then comes With examples that prove that stripping is identical to the words of the Arabs, and examples from the level of circulation among the general Arabs, he says: "This is the door of the predicate and the predicate, and they do not sing one of the other, and the speaker does not find it at all, it is the name of the beginner and built upon, which is the words Abdul Allah is your brother, this is your brother, and like that Abdullah goes, it must For the verb of the name, as the first name did not have to be the other in the beginning " $\left({ }^{5}\right)$.

The assets imagined by Sibawayh have proved their existence by examples from the rolling Arab talking. These assets give the reader the real forms of speech, but as the speaker leaves the deliberative level, he allows himself to transcend the assets. Sibawayh mentioned in the section of "Instead of knowing from negation, knowledge from knowledge, and cutting knowledge from knowledge beginning", then explained to imagine for that a verbal stance on the discourse and controversy, it is instead of knowledge of Good saying: "I passed a man Abdullah as if", as if he said to him, "Who did you go through?" Replace what I know of him, and such as Good saying: "You are to guide to the path of the right path of God," The Aljaheth 159-255AH found that the correct speech is the speech that is achieved correctly composite, and coordinated with the linguists stripped of the assets It must be taken into account, because the origin is the law and the comprehensive logical rule of the particles, "Arab understanding of your need for the streams of the words of the eloquent Arabs," and concludes from the words of Sibawayh and Aljaheth: that the origin in the composition to be consistent with the grammatical rule, which are rules devoid of the words of the eloquent. True in terms of meaning, the dysfunctional part of the constituent assets has lost its value as much as the displacement of the two components:

\footnotetext{
${ }^{1}$ Tamam Hassan - Origins - p. 123 - House of Books - Cairo - 2000.

2 See "Measurement in grammar" - d. Mona Elias - p35 - Dar Al-Fikr - Damascus - 1985.

${ }^{3}$ Statement and clarification - c 1 - p76 - Dar al-Fikr - Beirut - the investigation of Abdel Salam Haroun - without history.

${ }^{4}$ Book-Part 1- 25- Investigation of Abdel Salam Haroun - Egyptian Book Organization - 1977.

${ }^{5}$ Book - part 1 - p26 - and then see the platform of rhetoric and Al OdabaaSerag for Al Qurtaji - The realization of Habib bin Khoja - 1966 -

Meanings - 18-19.
} 
the validity of the composition, and validity of meaning.

Sibawayh's heuristic approach referred to the logical clarity, that is, the strict sequence in linking Al-Qaeda with the appropriate words of the Arabs, "the origins" and then transcending the origins. In the first, the process of clarity is diagnosed in the student's examination of the language, and in the second, the use of concepts becomes mandatory, because inferential knowledge plays a big role in ordinary and daily people, but its value is that it is private science, careful sequencing and appropriate employment is a necessary condition for success in language researc $\mathrm{AH}$

\section{Installation System and Space Meaning}

The space in which linguists and grammars moved was the space of "meaning", and therefore they consistently return synthetic images to the meaning they originally intended, for a single word, and for each composition, and about this military mention: "Meaning is the intent between saying on a face without a face, The meaning of speech in language may be attached to the intent " $\left({ }^{1}\right)$.

The meaning, then, is the speaker wanting in his talk, the purpose of the speech, the unequal wording, the change of speech systems between deletion and conspiracy, submission and delay, and other means intended to denote meaning only, and it is interesting that Al-As'kari has attributed the meaning of speech to the intention of the speaker in his speech, Linking the formula of speech and validity of meaning. And "truth" what he put from the position of them, it is said: I mean meaning "and wanted to mean that the truth signified by speech, whether I mean or not meant, when he meant the words of the speaker on the truth, or that the truth is some of what he aims, and when he throws be he put his words in the origin of the language, so it is the truth "What is said in the origin of the language is good or ugly." IbnJeni didn't get away from Al-As'kari, he said : "The truth is acknowledged in the use on the origin and put in the language" $\left({ }^{2}\right)$.

This is what the scientists of the fourth century, they have made the original or primary meaning is the truth to which the images of speech as evidenced by the changed and behaved. The Jurjani 472 difference of truth between the singular and the sentence, alone in the singular, which it is from the structure to the vocabulary.

Abu Obeida's investigation was not limited to the metaphor of synthesis, as it is the richest image in the Arabic styles, but his other effort devoted to the issue of vocabulary, and proved after his inspection that the individual - as for the synthesis - metaphor, and began to demonstrate the validity of his assumption on the Quranic vocabulary, and did not lose sight of Abu Obeida that the Quranic singular meaning within the context, among the many possible meanings outside the regularity in the verse, has been represented by the word "judiciary" as they follow their meanings in the Koranic texts, proved privacy for each time as good saying: (And your Lord decided not to worship except him) metaphorically and ordered "your Lord," and "we spent" metaphor told us, and in the Almighty says: (The Lord is spending among them) metaphorical "rule", and in good saying (And they judged seven heavens) metaphorical : created them $\left(^{3}\right.$ )

It also did not overlook the morphological form of the word, with regard to the meaning of what is contrary to its original significance, and this is the usual methods of the Arabs, such as the formula "faeel" as in Good saying inA-Namel, verse 78 (Those are the verses of the wise book), the word "wise" metaphoric arbitrator (Almufaal)"activated" clearly outlinedan in a tradition of the Arabs to put (faeel)"effective" in the meaning of (Mufaal) "activated", and in the verse 12: ( This is what I haveAted ) a metaphor prepared, and as Abu Duaib said: "I am Ghadaand did not feel Khalif." As if the poet said: I did not feel that I am a successor, from saying: I missed the date, the significance of the formula "Khalif-faeel" was not a continent in the word, which is outside this context, but the new significance generated by the language context, and concludes from this context that it is Gives the singular meaning you come out.

Since the subject in the "metaphor of the Quran" is based on the methods of the Arabs in their speech, the subject of the above mentioned clarification of the meanings listed on the azimuth used by the Arabs in the runways of her saying, interpreted the words in the text of the Quran on the guidance of the Arab poetry, as in verse 23. Do not rejoice, and metaphor does not point and do not have fun, including the words of Hadbai bin Khashram $50 \mathrm{AH}$ :

I am not happy if the eternity is my secret and I am not afraid to spend the volatile $\left({ }^{4}\right)$

After Abu Obeidalined the approach of "metaphor",Akhuffh Al-Awsat followed it $207 \mathrm{AH}$, he held in his book "The Meanings of the Quran" a section called: "This door of metaphor" and started from Surat Al-Baqarah 29. Akhuffhexplains a verbal formula that reveals the meaning of a word, but it differs according to its maker, and guides it to its purposes by knowing its vocabulary and its meanings. Which proves the proof that the Quran in the Arabic speech the object of the expression, it is strange and meanings .. As the predecessor and those who

${ }^{1}$ Abu Hilal military - differences in language - p25 - the Commission for the revival of heritage - New Horizons House - 9-1991

${ }^{2}$ IbnJnei - characteristics - a previous source - part 2 - 442 - Sahbi son of Fares from 321 - the investigation of Mr. Ahmed Saqr - I BabiHalabi - Cairo - 1977

${ }^{3}$ Metaphor of the Koran - a previous source - part 1 - p 370.

${ }^{4}$ Poetry of Hadba Bin Khushram Al-AthriYahya Al-Jubouri - Dar Al-Qalam - 1986 - Damascus. 
realized revelation dispense with the question about its meaning and what it is in the words of Arabs like him from the faces and the summary, found to consider the Holy Book on the guidance of the methods of the Arabs in her speech " $\left.{ }^{1}\right)$.

This is what Abu Obeida has repeatedly sought to show: that the methods of expression in the Qur'an do not depart from the methods of expression of the Arabs in her words, as if he were establishing a speech to the contrary to the apparent requirement, and does not stand at the problem of language alone, but is waiting for interpretation, including the words of Abu Obeida : "It is a metaphor of what was deleted and the implicit, he said: and asked the village where we were and the camel where we have accepted .. This is omitted in his conscience, metaphor: and ask the people of the village, and who in the Al-Eer" $\left.{ }^{2}\right)$.

Here is evidenced by the fact that Arabs may use tools in a sense other than what it is originally, and this is confirmed by Sibawayh in his talk about the preposition "in" he mentioned that the metaphor of the tools that have meanings "in various places, the tool of themcomes in some places for some of those meanings "He said:" To strike for example mosquito and above ", meaning and below, and said: "The land then Dahaha"and means with it. Then he concludes with a conclusion: "In the Koran what is in the Arabic speech of the strange and meanings, and possibly from the metaphor of the abbreviation, and the metaphor of what was deleted, and metaphor of what has stopped his experience, and metaphor of what came the word one, and signed on everyone, and metaphor of what came the word Everyone, its meaning fell on the two " $\left({ }^{3}\right)$.

In spite of the individual abilities of Abu Obeida, he relied on the efforts of its applicants, most notably Sibawayh, and took from him and what enabled him to enrich his stylistic research, and consolidates his links with the levels of Arabic speech, in an effort to establish the theme of "stylistic" in the early era of Arab science.

As good saying In the verse of Al- Baqara: (Would you make who spoil it), the method came as an questionnaire, and angels did not question the Lord, but the meaning of the positive, that is, you will do, and like the saying of Greer:

Are you the bestwho rides the Almataya and called the worlds ButoonRahi $\left({ }^{4}\right)$

The poet took the question out of its meaning, as if it were obligatory and he decided, and perhaps a word I want what happened to him in a situation, and if you like I said: in places - an incident in which it is not based on others is a fact ... because the description of the word as a fact or metaphor ruled in terms of It has an indication of the sentence, not in terms of Arabic, Persian or previous in the situation or updated generated, it is right limit to be so that it is in all the function words $\left(^{5}\right)$.

Then The latecomers knew the "truth" Al-Sakaki 626 AH define it as: "The word used in what is set for him, without interpretation in the situation to take care of metaphor, in metaphor is the word includes, as it is placed, the most correct sayings, and do not call it a fact, but metaphorically To build a suit alias subject to the alias him on a kind of interpretation $\left(^{6}\right)$.

\section{Stylistic metaphor \& Expression values:}

It was agreed that the idiomatic meaning of metaphor is only a combination of the two meanings of the word: transfer and permissibility of the thing metaphor of the other, although not identical to him, or an example as expressed by Ibn Fares, he said: "And says: We have dirhams and clear balance, and other permissible permissibility of balancing" This is not permissible, it is permissible to metaphor, and it is permissible for proximity to them $\left."{ }^{7}\right)$, then metaphor is a way of expressing the meaning, permissible permissibility of verbal formula for proximity to it, if we say" metaphor "is the real speech goes on his Sunnah, and others may be permissible because it is close to him, but there is a metaphor and metaphor and desist what is not in the first, as your saying: giving someone, this is analogy, and permissible metaphor as saying: "Tender many adequate" $\left({ }^{8}\right)$.

Although Sibawayh realized the idea of metaphor, he did not name it, especially when it made it a kind of expression of the meaning of convergence of origin and may be metaphored, while Abu Al-Abbas Almebrad $285 \mathrm{AH}$ was more clear, making orbit talk about the origin and out of speech, he measured saying: "There are two imperfections" , To say: "People in such a place," and said: "As for the words where the defects are derived from, because it made it like a bowl for the defects, and speech has an origin and then widen it in the form of its origin" $\left({ }^{9}\right)$

As for Muammar IbnAl-Muthanna, "Abu Obeida" $210 \mathrm{AH}$ has prepared the idea of the term, it is in addition to the accumulation of Arab science and news, have flexibility was not for other linguists, and the

\footnotetext{
${ }^{1}$ Al-Mizhar in Al-Suyuti Language Science, previous source, part. 2, pp. 402-403.

${ }^{2}$ Metaphor of the Quran to Abu Obeida - Achievement of Mohammed FouadSarkin - Khanji Library - Cairo - pp. 13-15.

${ }^{3}$ Ibid., part. 1, p. 88 .

${ }^{4}$ DiwanJarir - Beirut House for Printing and Publishing - 1986

${ }^{5}$ Secrets of rhetoric - previous source - p. 303 - investigation Mahmoud Shaker - Alkhanji Library - 1991 - 1st.

${ }^{6}$ The key to science - Sakaki - pp. 152-153 - Achieving NaimZarzour - 1987 - I 2 + the basis of rhetoric for Zmkhshari.

${ }^{7}$ Tongue of the Arabs - part 3, p. $326+$ Al-Mehwari rhetoric basis, p. 69.

${ }^{8} \mathrm{Sahabi}$ - a previous source - p. 322

${ }^{9} \mathrm{Sahbi}$ - the previous source - the same page.
} 
people of his time attest to his broad horizon in the aesthetic aspects of language, was much comparative Among the artistic images, then he deduced the new ones, and his famous work "Metaphor of the Quran" was an attempt to look deeply into the Quranic text in terms of language and style, and in his work mentioned the idea of the analysis of the Arab structure as a Quranic vocabulary, stressing his saying in the "methods of saying" which Graduated on the apparent need, and not only the Al-Akhfash Al-Awsat that took place in the space of Abu Obeida, has also followed his approach Yahya bin Ziyad Al-Gharar 207 AHandAljahith 255 AH, refrigerant 285 AH, IbnQutaibaDinuri $276 \mathrm{AH}$ and IbnFaris $395 \mathrm{AH}$, they have concluded that the "metaphor" formula of expression made by the world secrets of language, and who is able to measure in its actions on the Sunan Arabs in her speech

\section{The Issue of Pronunciation and Meaning:}

This issue occupied most of the linguists, grammar and rhetoric, and the issue of symmetry between them and proportionality were the most important assets adopted as a criterion for the study in this area, and the occasion between them was not originally in linguistic research firmly, had it not been that the other solid origin is the "usefulness of speech" has been shortened the issue of interest and relationship Speaking by saying: "What is useless there is no sense to speak by" $\left({ }^{1}\right)$. So the origin of speech perform meaning, and the meaning is only performed by the most appropriate and complete pronunciation.

Then adopted another asset that does not contradict the previous original, but based on it, which is "indicative of the meaning of the word" and should not be reversed only by establishing the evidence, has originally this Abdullah bin Muslim bin Qutaiba by saying: "The origin in each letter to be indicative of what was set for him Originally, whoever stuck to the original had stuck to the companion of the case, and whoever changed the original remained dependent on the establishment of evidence $\left(^{2}\right)$.

The Al- Mebrad Abu al-Abbas identified another original term for the meaning of performance, which is to tell something that is not self-evident, or not worthy of telling him, he said: "Do not you see if you said: a man standing, and a man of the world ${ }^{3}$, it was not in these words useful, because it does not He denounces that there is an existing man or a scientist. So there must be another word that takes the word out of its "generality" to "its property."

One of the assets adopted in the pronunciation and meaning of the relationship of the parties to the levels of listeners, and taking into account the shrines that they are, and this is called for by Bishrbin Al-Mu'tammar 210 AH-825 AD Al-Mu'tazili, one of the founders of rhetoric thought in the Arabs in his "newspaper" in learning emerging rhetoric "The speaker should know the fates Meanings, balancing them with the fate of listeners, and makes for each class words, and each case, so divides the magnitude of the meanings on the fates of the shrines, and the fate of listeners on those cases " $\left({ }^{4}\right)$.

In the Original effect adopted by Bishr binAl-Mu'tamir, Zia Al-Din IbnAl-Atheer, 585-637AH, divides speech into types, some of which are characterized by the economy, which is to have the implicit meaning in the phrase as required by the expression in his status, and some related to excessive, Against that, the meaning is in the phrase without what is required by the status of the expressed, and the other: that the meaning is above its status ... It is strange that you see two words denote the meaning of one, both good in use, and are on the weight of one and several, but it does not improve the use of these in every place where these are used, but differentiate between them in the founding positions, it is the saying (God made a man of two hearts in his inner) Al-Ahzab (4), and he said in Al-Imran (35) (My Good I vowed to you in my belly free) so use the hollow in the first and the abdomen in the second, and did not use one of them replaced the other, and the two words both in significance " $\left({ }^{5}\right)$.

And beforeIbnAl-Atheer, Al-Jaheth had stipulated to good speach "the choice of the word in good understanding." Al-Jaheth also called for a summary by saying: "brevity in rhetoric", The rhetoric is the "revelation", not the crowd, but the rhetoric celebrated the division of speech according to its relevance in the sense, so they made rhetoric in three tracks: equality, reference, and humiliation.

TheEquality is to be the word as a template for the meaning, it is not preferred, and does not diminish, but the reference is that the word is referred to the meaning as a glimpse of the function, and the humiliation is to return the synonyms on the same meaning" $\left({ }^{6}\right)$. When the conflict between the two schools of Kufa and Basra intensified over the relation of the word to the meaning, the Kufites clung to the apparent, and the visuals stuck to carry the word on the meaning for a purely moral purpose, so the interpretation was the most important doctrines of the grammarians to return speech to its origin epically in once the word was used as a means of

\footnotetext{
${ }^{1}$ The Animal - Investigation of Abdul Salam Mohammed Haroun - Dar Al-Jeel - Beirut - c.

${ }^{2}$ Interpretation of the problem of the Koran - Scientific Books House - Beirut - I 3 - 1981 - p. 20.

${ }^{3} \mathrm{Al}$ Muqtadeb- The world of books for printing and publishing - The Investigation of Mohammed Abdul Khaliq - Beirut - 1936 - c 4 - p. 86.

${ }^{4}$ On the likenesses and isotopes of Suyuti - part 1 - p140 - the linguistic complex in Damascus - 1986 - the Realization of Abdul IlahNabhan

${ }^{5}$ The proverb in the literature of the writer and poet - Achievement Ahmed Hofi + BadawiTabana - I2 - Dar Rifai - Riyadh - part 1.

${ }^{6}$ Concepts of aesthetic and criticism in the literature of the bigeye - d. Michel Assi, Naoufel Foundation, Beirut 1981, p. 36.
} 
separating the original from what was beyond the words, they were confirming the idea of "origins" and the idea of departing from it, and the ultimate goal was to reach the origin of meaning. So, IbnSeraj saw in Good saying in Al-Israa (72): (He who is in this blind is in the Hereafter blind and lost way). He saw in the "blind" of the blindness of the heart and attributed to astray, and here we say: what blinded him, and the "blind" second is not intended to be blind from so, it is blind eye, is not uneven.

\section{Components of Stylistic Metaphor:}

We have already mentioned that Obeida bin Muammar bin MuthannaAl-Tamimi in his work "metaphor of the Quran" has laid the foundations of stylistic science, through his view of the Quranic text analytical stylistic view, did not adopt external factors in the study of the "text", but began from the inside of the text, trying to reach to the most important components of the "stylistic metaphor" Stylistic metaphor by comparing with the Arabic texts and methods of its creators, and has laid the theoretical basis for this problem by saying: What stopped his experience, and metaphor of what came the word everyone and signed its meaning on the two, and metaphor what came the word of everyone on the news of one, and metaphor of what everyone came in one place ... and metaphor of the word animal and death on the news of people, and metaphor of what came to address the absent means to address the witness ... The backside ... and in all these doctrines came down the Quran " $\left({ }^{1}\right)$. Then became his study of the text of the Koran based on the other, and the most important vocabulary stylistic study $\left({ }^{2}\right)$ :

- Submission and delay: As the first Good saying: Al-Baqara (187) (If we send them water shaken and patted) on the submission and delay means patted and shaken.

- Deletion and Atrophy: It is estimated the verse: (BismillahiAl-RahmaniAl-Rahim, omitted and made it metaphor of deletion at the discretion: "This Bismillah, or Bismillah everything."

Holding on the meaning and pay attention:And make it the his addressing section to address the absentee as said : (Alf Lam Meem, that book)Hood (41), metaphor " Alf Lam Meem, this book."

- The Analogy:his majesty said: (Your women plow you)Younis (22), he said: metaphor and analogy.

- Representation: has made it a kind of metaphor as in the verse: (On the brink of a cliff), and metaphor of the verse "What was built on piety has proved a foundation of building on disbelief and hypocrisy.

The stylistic research of the ancients continued to rely on the foundations of Abu Obeida until the fifth century, where the first Hijri centuries led to Abdul -QaherJirjani $472 \mathrm{H}$, to begin a new way in his research "Signs of Miracle" on the methods of Arab and stylistic characteristics.

\section{MetaphoricallaNguage}

Through the work of linguists and rhetoric's that metaphor as a term with many spaces, the most important metaphor and representation and heart and presentation and delay, and deletion and repetition and concealment, and exposure and disclosure and metonymy and clarification, and address one address everyone, address everyone address one, and one and everyone speech, and the intent to utter particular meaning the whole, and the pronunciation of the general meaning of particular $\left(^{3}\right)$.

IbnQutaybah's attempt seems to be a dual project. The first part is based on the "Metaphors of the Quran" by Abu Obeida. The second part is an attempt to draw a theory on the use of "metaphors" in the words of the Arabs, and their writings.

It is evident from the work of IbnQutaiba his understanding of the nature of the text, regardless of external factors, which prepared for many researchers after him focus on the nature of the text, and the separation of nature and function, and then the relationship between them. But IbnQutaiba always warns of mistake "interpretation", and gives a witness of the mistake of "Christians in interpretation and splitting into bees, and if they carried the text on the metaphor they would have known the truth and away from the analogy" ... This is what some Muslims signed when they carried the speech on the face As some of them did not recognize the metaphor, others took extravagance in carrying texts on it, so they carried the word of God to the metaphor. They saw that it was neither a word nor a word on the truth, but it is to find the meanings, analyzed in many of the Koran to the metaphor, saying the saying "and said your head to me" wants his own tendency "( $\left.{ }^{4}\right)$.

IbnQutaybah is the scientific heir of Al-Jahith in his encyclopedia and his many works, and although he did not leave a rhetorical writer, like the protagonist, his encyclopedia contained many rhetorical references, as in "poetry and poets" based on some of the critical provisions, and these provisions The singer's contribution to criticism in Arabic rhetoric, while his book "Literature of the writer" was concerned with civilization, organization and administrative factor, and was an indication of the emergence of the royal literature needed by the Royal Institution.

\footnotetext{
${ }^{1}$ Interpretation of the problem of the Quran - IbnQutaiba - Scientific Books House - Beirut - p20 - a previous source.

Ibid., part. 1, pp. 12--11-11-73.

${ }^{3}$ Interpretation of the problem of the Quran to Abdullah bin Muslim bin Qutaiba - House of scientific books - Beirut - I 3 - 1981 - p 14.

${ }^{4}$ Ibid., Pp. 14-15.
} 
His book "Interpretation of the Problem of the Qur'an" is his most authoritative work on rhetorical research, and we have no explanation about this except to acknowledge that the doctrinal factor and the defense of the Qur'an were the decisive factor that forced scientists to adjust rules and establish borders for urgent practical purposes. Blocking the door of opinion and attempts to question and intrigue " $\left({ }^{1}\right)$.

It is clear that "interpretation" is directly related to the apparent expressions, and shows that departing from the familiar phrase does not change the same meaning, but another additional meaning, is added to the original meaning, hence the synchronization process between the original and the modified versions is necessary, then search The continuous interpretation of each term for a suitable term for the form and quality of the amendment, a strict for any tampered wanted to tamper with the Quranic text, and was the "interpretation" from this side starting to an unknown basis of information, in order to preserve the process of interpretation of the imbalance, and directed towards the accuracy of the conclusion, and here confirms IbnQutaiba "But he knows the virtue of the Koran much of his eyes, and expanded his knowledge, and understanding Arabs are going, and a fascination with the methods, "and singled out by language without all languages. And that metaphor is considered a common denominator greater between the languages, and the need to express inevitably riding it turns out to those who knew the language to say that metaphor and the superiority of Arabic over other languages to the intensity of its people in the statement and their breadth in the metaphor $\left(^{2}\right)$.

Interpretation was not emancipated from historical transmission arguments, and found its dimension in the body of linguists who preceded the stage of the protruding 159-255 H, those taken from the Islamic "blog", especially the Quran for their work, and the most important researchers in the period cited by fur and Abu Obeida, as the concept of metaphor have a foundational basis for the concept of the son of Qutaiba.

According to the Tunisian rhetorical thinker Dr. HammadiSamoud: "The Quran is a technical text whose methods do not depart from the framework of special positioning of the methods of the innocent Arabs, which is a refusal from the usual use of ordinary ... And absent from the theory of miracles in the Arabs that we do not find in the history of the miracle of the Quran - in all its writings - link miracles These faces and methods, and the reason that the text of the Quran to distinguish from other human speech - including literary speech - must be a departure from the exit itself, otherwise the hero of miracle .. Then these faces and methods learn, and science and miracles contradictory statements, so they will look for paths and phenomena others explain it $\left(^{3}\right)$.

When he speaks linguistic or rhetorical in the miracle of the Quran, but to show that it exceeded the words of the Arabs in fact and metaphorically, and to prove that the upper ceiling that does not reach the illusions of a writer, nor suspicions of a poet, if the words of writers and their methods out of the ordinary metaphor, the Quran is a departure from the methods of rhetoric and writers and his miracle out of the exit, any transgression of the Arab metaphors, including their poetic creations, and the position of IbnQutaiba pro-poets against the ultralinguists as a result of his nature to defend the metaphor and his optimal presence in the Quranic text.

The metaphor of the opinion of IbnQutaiba includes sundries of methods, which he calls on all types of metaphors typical to date, and metaphor on the changes in the performance paths, whether related to the sentence or the word, and metaphor narrower than the metaphor in his opinion.

In the section of deletion and abbreviation, he evoked the evidence from the Quran and poetry, mentioning the deletion of the additive and the establishment of the additive to his place, and make the actor as God saying: (Ask the village where we were) Joseph (82) any tuberculosis of its people, and from him to come to speak indicating that he has an answer to delete the answer in abbreviation of the address to the (Except God's grace and mercy, and that God Rauf Rahim) Al-Nour(20). IbnQutaiba commented: He wanted the Almighty: "He wanted to torment you." $\left({ }^{4}\right)$

\section{The Third Century Marker:}

Al-Jaheth was the scholar of the third century, and he filled the private and public with "graphical" in an era that philosophy had removed the Arabic sciences, he returned Al-Jaheth graphical to the center, and the term statement does not indicate when the big one, it is indicative of the means of expression, and sometimes indicates another on the linguistic relationship, as a complete tool that enables the owner to fulfill his need to express his inner and outer worlds, was opened by a funny cognitive pattern. $\left(^{5}\right)$.

Al-Jaheth did not forget the linking the growth of language and the life of thought, within a vision is not without philosophy, as the idea is not separated from what it performs, as if it proves that the language revival of the meanings, and out of the state of existence - nothingness and invisibility - "If a person left to say his thoughts died, and dissipated Himself and spoiled his sense" $\left({ }^{6}\right)$.

\footnotetext{
${ }^{1}$ Dr..HammadiSamoud - rhetorical thinking among the Arabs - publications of the Faculty of Arts - Manouba - Tunisia - 1994 - p 327.

${ }^{2}$ The interpretation of the problem of the Koran - a previous source - p. 109-20

${ }^{3}$ Rhetorical thinking among the Arabs - a previous source - p. 331.

${ }^{4}$ Rhetorical thinking among the Arabs - a previous source - p 340

${ }^{5}$ Ibid., P. 174.

${ }^{6}$ Statement and explanation - part 1 - p. 272.
} 
It seems that Al-Jahethmay be alert to the components of the linguistic verb, he found three: the speaker, hearing and speech, but acknowledged that the function of the basic language is "understanding and understanding", without which other functions cannot perform its functions, and the protester is keen to perform functions within the terms of eloquence and rules. He then concludes that the function and the demonstration produced the components of each of the parties of the language process, especially the speaker and speech, and since he identified the components of the linguistic verb he identified the components of the graphical formula, namely: rhetoric, rhetoric and eloquence, and then pointed to an important aspect, which is the distinction between theoretical laws in the quality, What leads to the whims of use. "People use other words to do so deserving of them, or at least accept the commonly used words, and leave what he showed, and more, as well as with that hair ..." $\left({ }^{1}\right)$. He was keen to concentrate power - the power of the word and knowledge - in the hands of the Arab race, in the different society of the Caliphate State "meanings known by the Arab, Ajami, rural and Bedouin," a reference to the fortunes of people living in the House of Islam is preserved, while the disparity in form and formulation.

In the fifth century, Al-JurjaniAbdAl-Qaher appears in 400-472AH- $1087 \mathrm{AD}$, separating from the third and fourth centuries, and continued with them, ahead of his advancers in time $\left({ }^{2}\right)$. He showed what was not clear from them, he saw metaphor "that the subject that you prove by the meaning does not know the listener that meaning of the word, but knows the meaning of the word, such as saying:" I saw a lion ".. When you say this phrase is intended to prove to the man. He does not make sense of the word Assad, but it makes sense of the meaning .. He knows that it makes no sense to make him a lion knowing that he is a man, but if you want that he reached the severity of similar to Assad the amount of fancy with him that Lion truth $\left(^{3}\right)$.

If Jurjani acknowledged the understanding of the protector of the metaphor, and then expanded it, he refused to define others, which says: "It is the comment of the phrase other than what was put in the origin of the language for transport," and felt that this is not true because "metaphor does not mean the transfer of the name of But to claim the meaning of the name for something" $\left({ }^{4}\right)$, and then devoted the idea that the metaphor is based on naming something with the name of another for moral significance, but that does not mean a change in the meaning of this name, in order to express an ambiguous cloudy meaning the original word on his performance, and gives a witness is "told by Imran who built it" says: Imran taken from the old, which is to stay, if the man remains In his home, he lost her life, and Jarjani showed that the understanding of the Al-Jaheth is accurate, if the meaning is seen through the same pronunciation of the meaning of what is meant, and to understand from the phrase a contradiction occurred, and the truth as the Al-Jaheth saw is that the poet says: Because the days are influential in things inferiority and wear and tear, when the ruin remained in them and the place of urbanism in others called Urbanism " $(5)$. The word urbanism here did not shift from its meaning, which is "survival", but placed in a different context, and it had a special meaning for the concept of survival.

Al-Jaheth did not stop at the metaphor, but illuminated towards another metaphor, the metaphor sent, and founded him in the "animal", and the evidence that he gave the Al- Nahel 69 (He get drink of different colors comes out of its stomachs, which heals people) He decided that the drink in the verse is honey, but God has transformed the significance of the drink into a new one, namely "honey". The original, honey turns into a mixture of water-mediated syrup, it is not a lesson in taking honey from the stomachs of bees, but rather to take it out to be useful.

Obviously, Al-Jaheth has invested the efforts of jurists and speakers in his rhetorical approach, while AlJurjani has invested the efforts of fundamentalists, linguists and interpreters in establishing the science of meanings "signs of miracles." In parallel to the Jaheth, he founded the "science of Badeea".

Through the project of Jurjani, we see that in his project rise above the project of the protruding the fifth century to the third, as it struck a page on the decoration of the protruding decorations in order to create the "vitality" of the language to be the historical bearer of the era of "intellectual" and surely the "miracle of the Quran" form the roofed space And the development of linguistic thought, and the resultant, and put an end to the discretion of speakers, and did not hide Jurjani that the search for the secrets of miracles of the supplements of the message of Muhammadiyah "The party in which the argument made the Quran and appeared and expressed, is as if on the level of eloquence fall short of human forces, and Very not aspiring to thought, was $\mathrm{m}$ Immediately to know that as well as only knew the poetry, which is the Arab Diwan and the title of literature .. Then look for the ills by which the disparity in credit, and increased some poetry on some " $\left({ }^{6}\right)$.

Al-Jurjani would not have stood at the temporal boundaries. A holistic thinker who transcended rhetoric and its characteristics to the world of criticism and its problems, literature and his men, who laid down his

\footnotetext{
${ }^{1}$ Statement and clarification - part 1 - p. 20.

${ }^{2}$ Evidence of Miracle - part1 p.202.

${ }^{3}$ Statement and Clarification - part 1 - p. 202

${ }^{4}$ Animal - part 5 - p. 423 - investigation of Abdul Salam Mohammed Haroun - printing press Mustafa Al-Halabi - Cairo - 1965 - 2nd.

${ }^{5}$ Animal - part5- p. 423

${ }^{6}$ Evidence of Miracle - Previous Source - pp. 6-7.
} 
comprehensive project in his book: "The Parable in the Literature of the Writer and the Poet", an encyclopedic attempt in which he combines machines and naming them, asking himself an inductive question: How does the text form? Referring to the idea of creativity between individual characteristics and quantitative accumulation of knowledge, and then resulted in his question another question: How does the text change? Here is a question aboutRhetoric, says about the structure of his book: "Its structure on the introduction and two articles: The introduction includes the origins of the science of statement, and the two articles include its branches, the first in verbal industry and the second in the moral industry, and if you leave the passion, I said: This book is wonderful in his alienation and has no owner Books " $\left({ }^{1}\right)$.

It is clear that Ibn Al-Atheer is responding to the calls of his time, so that he separates from science, so that the boundaries between the statement, literature and criticism, and between the sciences of language and other sciences, appear to be clear. . This chapter was a methodological necessity commensurate with the seventh century in which language science began to decline as an independent science centered on its methodology, and progress as a means for the growth of science in nature, sports and philosophy, and on the temporal parallel to DiaaAlddinIbnAl-AtheerHazimAl-Qartagni 554-684AH- 1285 AD, which shows a science, Moroccan parallels Mashreq sciences through his famous author "The Platform of Prostitution and Siraj Al-Adbaa", Hazem collected the sciences of language and theology and studied their elders, then he studied rhetoric and poetry, then ventured into the study of philosophy, especially the philosophy of Al-Farabi 260-339 AAH- 950 AD and then focused on the study of IbnSina $427 \mathrm{AH}$ and then devoted to the study of philosopher IbnRushd 520-595AH$1198 \mathrm{AD}$, The problem of "statement" from a structural linguistic problem to a knowledge problem as a means of performing the expressive energy of the sciences of nature and philosophy, putting the problem of rhetoric through the "curriculum" within the problem of internal and external, Arabic and Greek sciences, which is the first attempts to cut the professorship of the Oriental heritage, in order to build His own space through culture with the Greek heritage, especially the Aristotelian, and therefore considered the "curriculum" a separation between two times: the Arab Orient and the new Moroccan time from the Greek uterus, as if out of the thresholds of language to the space of intellectual.

\section{Summary and Results}

The foundations of metaphor have shifted from scattered formulas in books of literature, language and other sciences, to rules with special features, laid down in their bitumen form, formed by rhetoric's, linguists, critics and philosophers, each in his own way, in theoretical frameworks derived from applied lessons.

- Philosophers had an active role in the progress of the idea of metaphor, after the rhetoric's handed the matter to the philosophers in the stages of the international culture of the peoples of the Caliphate as a first step, and then educating with the outside "Greece" as a next step, and Farabi marked the transition from "procedural" discourse to "literary" discourse. That is, to the literary language, by dividing the history of the language into stages, starting with "stability of the words on the meanings" and the second phase is the transcription and transcendence in the phrase and words, and the words became widening and denote the meanings that were not developed, and this idea was confirmed by IbnQutaiba and AljahetAH

- Most of the Muslim philosophers went on to believe that the poetic saying is a changing saying, that is, if the direct or real say is not true called poetry or poetic words, and here poetry means "metaphorical method."

- And the idea of changing the word from truth to metaphor resulted in the idea of "Al-Adul", a term through which the rhetoric as a sign of the evolution of the metaphorical lesson, and from it began Jurjani, and found that the metaphor and metaphor to represent the "Object on the Metaphor" is what Hassan returns to the word without systems.

- The rhetoric filled themselves with the nature of the metaphor, so they went into its study in detail and in aggregate, and they were not on one direction in understanding the nature of the metaphor. Al-Jirjani said that the metaphor is "every word I want other than what happened to him in a position drawn up by a note between the second and the first... or" every word. You may attribute what happened to him in the position of the unassigned to what has not been placed without him to resume a situation in which to note between what may be to him and the origin that put him in the position of the author.

- The rhetoric distinguished between the metaphor that lies in the singular and the metaphor that lies in the composition, and the pioneer of this distinction Aljurjani himself, as he in the metaphor singular to the problem of "status", which is the primary meaning of the word or original, and metaphor is based on the will of the speaker, and provided that the metaphor Copies of the descriptive meaning in order to replace the metaphorical meaning.

- Distinguish Jurjani between metaphor, as in your saying "I saw a lion" and you want to say "I saw a man similar to the lion" did not suspect that the second need the first, and metaphor sent.

- There are two ideas related to metaphor: transport and replacement, two ideas are similar and overlap, and

${ }^{1}$ The proverb in the literature of the writer and poet - a previous source - p. 47 
perhaps the suspicion of receiving Aristotle's definition of "transfer of the name of one thing to another", and the word transfer in the language of Aristotle Substitution means replacement, ie, the replacement of the word, which means - without doubt - transfer Meaning from one expression to another, and this is alerted by the King Bin Sanaa 608 AH in his book "House style in the work Almowshat".

- Roman grammatical T 386 e was one of the scholars who argued that the metaphor is based on the transfer of "transfer of the word" from one indication to another, and built his definition "metaphor apply the phrase to what was put in the origin of the language on the transport to be clear.

- Al-Jurjani was interested in two levels: depth and surface with mental metaphor, employing his knowledge obtained from the sciences of the language and the sciences of his time in distinguishing between truth and metaphor, which made him the holder of composition.

- The rhetoric took care of the question of clues, the presumption is the understanding of speech, However, they set out to borrow the condition of the presumption that the listener is able to understand clearly.

- I did not release rhetoric from the distinction between the original meaning and the metaphorical meaning, and was stipulated by Jurjani, then explained Sakaki 626 e that the meaning of the metaphor "is infringing the word on its original concept, by knowing the context to others to note between them and the type of attachment." 